J. Clin. Chem. Clin. Biochem.

Vol. 25, 1987, pp. $437-440$

(C) 1987 Walter de Gruyter \& Co.

Berlin - New York

\title{
Assessment of an Automatic Liquid Chromatograph for Foetal and Abnormal Haemoglobins
}

\author{
By S. Brenna, L. Prencipe, S. Granata and N. Montalbetti \\ Laboratory of Clinical Biochemistry and Hematology Ca' Granda - Niguarda Hospital, Milan, Italy
}

(Received December 4, 1986/March 12, 1987)

Summary: The DIAMAT TM (Bio-Rad) analyser is a microprocessor-operated HPLC system using a silicabased weak cation exchange column with three phosphate buffers of increasing ionic strength as the step gradient mobile phase. A dual wavelength detector measures absorbance at 415 and $690 \mathrm{~nm}$; each sample is completely processed in 8 minutes. The instrument effectively separates and quantifies $\mathrm{HbF}$ in a discrete peak. We have verified that the $\mathrm{HbF}$ assay is linear up to about $65 \%$ values.

We calculated within-run imprecision for $n=20$ in 3 different haemolysed blood samples; the results are shown below as percent of total haemoglobin:
A) Mean $=1.06$
$\mathrm{SD}=0.048$
$\mathrm{CV} \%=4.5$
B) Mean $=1.90$
$\mathrm{SD}=0.041$
$\mathrm{CV} \%=2.1$
C) Mean $=8.93$
$\mathrm{SD}=0.047$
$\mathrm{CV} \%=0.5$

Between-run imprecision for similar samples $(n=18)$ was:
D) Mean $=3.74$
$\mathrm{SD}=0.20$
$\mathrm{CV} \%=5.5$
E) Mean $=9.94$
$\mathrm{SD}=\mathbf{0 . 1 5}$
$\mathrm{CV} \%=1.5$

Accuracy was assesșed in different series by correlating $\mathrm{Hb}$ values (y) with those obtained by the alkali denaturation test $(x)$. The regression line equation was $y=1.03 x-0.33(r=0.999, n=62)$.

The DIAMAT TM instrument also reveals the presence of any HbS and calculates its peak area correctly, as we found by electrophoretic reassay in heterozygous subjects. We also noted the presence of other abnormal häemoglobins characterized by specific retention times.

\section{Introduction}

In normal adult blood, foetal haemọglobin ( $\mathrm{HbF})$ accounts för not more than $2 \%$ of total haemoglobin. $\mathrm{HbF}$ up to $20 \%$ of total can be found in heterozygous cases of $\beta$-thalassaemia, hereditary persistence of foetal haemoglobin (HPFH), and in double heterozygosis with $\beta$-thalassaemia plus one haemoglobin variant such as $\mathrm{HbC}, \mathrm{HbS}$ or $\mathrm{HbE}$. Finally, $\mathrm{HbF}$ concentrations exceeding $70 \%$ of total $\mathrm{Hb}$ occur in homozygous $\beta$-thalassaemia, $\delta$ - $\beta$-thalassaemia, and hereditary persistence of foetal haemoglobin.

One widely used method for assaying $\mathrm{HbF}$ is based on its resistance to alkali denaturation (1); this method, however, is poorly sensitive to high $\mathrm{HbF}$ concentrations. 
Two methods used routinely are haemoglobin electrophoresis on cellulose acetate at an alkaline $\mathrm{pH}$ (2) and on agar citrate at an acidic $\mathrm{pH}$ (3), each being suitable for separating different haemoglobins.

Isoelectric focusing affords excellent resolution (4); but the method is remarkably complex and its use in the clinical chemistry laboratory is restricted for the time being to research work.

Other methods for assaying $\mathrm{HbF}$ are radial immunodiffusion (5), cation-exchange micro-chromatography for eluting "fast" haemoglobins (6), and some variants of ion-exchange high-performance liquid chromatography (HPLC) $(7,8)$.

The DIAMAT TM apparatus is a high performance liquid chromatography analyser originally intended for the automatic assay of glycated haemoglobins. The same apparatus, however, also quantifies $\mathrm{HbF}$ in a separate peak (fig. 1), as well as HbS, if any, and other abnormal peaks.

The possibility of complete automation of these assays, offered by the DIAMAT TM instrument, prompted us to test it for accuracy and reliability in the screening of abnormal haemoglobins, primarily $\mathrm{HbF}$. The more laborious methods of electrophoresis and alkali resistance were used for confirmation.

TIME 86-07-15 16:47

\begin{tabular}{lrrrr} 
& SAMPLE & NO. 011 & \\
NAME & \multicolumn{1}{c}{$\%$} & TIME & \multicolumn{1}{c}{ AREA } \\
AlAB & 3.2 & 2.5 & 189.71 \\
F & 16.8 & 3.4 & 1001.79 \\
AlC & 3.1 & 4.4 & 169.57 \\
A0 & 76.9 & 6.1. & 4574.13 \\
HBAIC & $3.1 \%$ & HBAI & $6.2 \%$
\end{tabular}

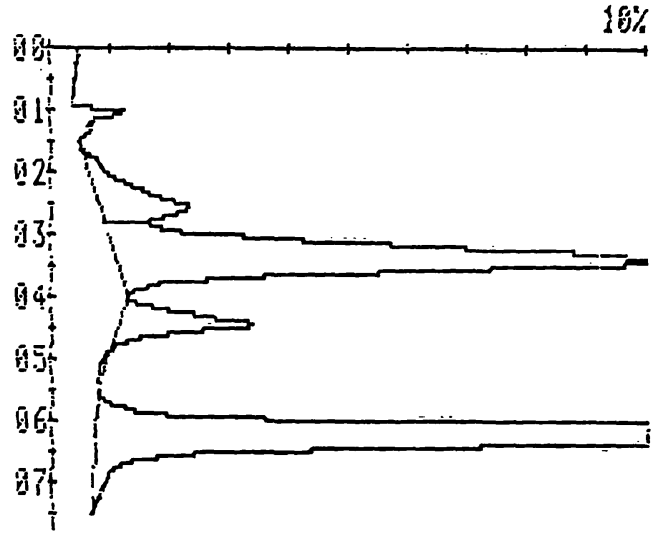

Fig. 1. Printout of sample with high HbF.

\section{Materials and Methods}

High performance liquid chromatography analyser

The Bio-Rad DIAMAT TM instrument is an automatic analyser utilizing the principles of ion-exchange high-performance liquid chromatography for assaying glycated haemoglobin. The apparatus features a single piston pump with a step-gradient valve system that allows three phosphate buffers of increasing ionic strength and different $\mathrm{pH}$ to run through the analytical column in a timed sequence.
First solution:

Second solution:

Third solution, phosphate buffer, phosphate buffer,

phosphate buffer,

$$
\begin{array}{rl}
90 \mathrm{mmol} / \mathrm{l} & \mathrm{pH}=5.9 \\
140 \mathrm{mmol} / \mathrm{l} & \mathrm{pH}=5.8 \\
270 \mathrm{mmol} / \mathrm{l} & \mathrm{pH}=5.7
\end{array}
$$

The column $(4 \mathrm{~mm}$ i.d. $\times 15 \mathrm{~cm})$ is packed with a weak cation-exchange resin in bead form; the support is silica with a carboxymethyl functional group. Buffers are eluted in the following order:

buffer 1: 1.7 minutes,

buffer 2: 2.0 minutes,

buffer 3: 2.1 minutes and

buffer 1: 2.2 minütes.

Thus, each sample is completely processed in 8 minutes. Haemolysed blood samples are stored in the refrigerated autosampler chamber until a $5 \mu \mathrm{l}$ portion is automatically injected into the column thermostated at $23^{\circ} \mathrm{C}$.

Readings are made at 415 and $690 \mathrm{~nm}$, to eliminate problems of turbidity or light source instability.

All operations are controlled by a microprocessor. The printout is a summary of $\mathrm{HbA}_{1} \mathrm{c}$ and $\mathrm{HbA}_{1}(\mathrm{a}+\mathrm{b}+\mathrm{c})$ values as well as of the relative (area) percentages of all resolved haemoglobins.

\section{Alkali denaturation}

We used the method of Singer et al. (11).

\section{Alkaline-pH haemoglobin electrophoresis}

For this we used the completely automatic OLYMPUS AËS 2000 apparatus. Electrophoresis was conducted on SARTORIUS cellulose acetate strips at $4 \mathrm{~mA}$ for 35 minutes in TRIS= EDTA-glycine buffer at pH 9.2 with semi-micro seeding, and strips were stained with Ponceau Red.

\section{Sample treatment}

For comparison and reproducibility tests in the DIAMAT TM series we used fresh venous blood samples with EDTA added as anticoagulant. Before analysis, the blood was haemolysed and diluted 1:200 with a solution of polyoxyethylene ether in borate buffer, volume fraction 0.001 .

In such haemolysates, even if stored at $-20^{\circ} \mathrm{C}, \mathrm{HbF}$ is not very stable from day to day; thus for assessing between-run precision we used two blood samples of high and low $\mathrm{HbF}$ content stored in the refrigerator.

For haemoglobin electrophoresis, suitable portions of whole blood were washed repeatedly with isotonic saline solution. We then treated 1 volume of red blood cells with 1 volume of water and $1 / 2$ volume of toluene. 


\section{Results}

\section{Linearity}

To verify the linearity of $\mathrm{HbF}$ assays we mixed a sample of neonatal blood $(\mathrm{HbF}=85 \%)$ in 20 different portions with adult blood of equal haemoglobin content and no appreciable $\mathrm{HbF}$ content, thus making 20 serial dilutions of $\mathrm{HbF}$ from 0 to $85 \%$.

From the first 4 points ( 0 to $12 \% \mathrm{HbF}$ ) we calculated the linear regression for the $\mathrm{HbF}$ values expected from dilution and those actually produced by the DIAMAT TM instrument.

The remaining points were never more than $5 \%$ away from the theoretical line, except for $\mathrm{HbF}$ contents exceeding $65 \%$.

\section{Precision}

Within-run precision was assessed in 20 replicates of 3 blood samples with different $\mathrm{HbF}$ contents.

$\mathrm{HbF}$ readings are expressed as percentage of total $\mathrm{Hb}$ :

Sample A: mean $=1.06, \mathrm{SD}=0.048, \mathrm{CV} \%=4.5$ Sample B: mean $=1.90, \mathrm{SD}=0.041, \mathrm{CV} \%=2.1$ Sample C: mean $=8.93, \mathrm{SD}=0.047, \mathrm{CV} \%=0.5$

The between-run precision test (18 replicates of 2 pathological samples) gave:

Sample D: mean $=3.74, \mathrm{SD}=0.20, \mathrm{CV} \%=5.5$

Sample E: mean $=9.94, \mathrm{SD}=0.15, \mathrm{CV} \%=1.5$

\section{Method comparison}

Accuracy was assessed in different series by correlating $\mathrm{HbF}$ values (y) with those obtained with the alkali-denaturation method $(x)$ in the range of 0 to $70 \% \mathrm{HbF}$. The linear regression equation was:

$$
\mathrm{y}=1.03 \mathrm{x}-0.33 ; \mathrm{r}=0.999 ; \mathrm{N}=62
$$

\section{Carry-over}

We investigated sample related carry-over in the DIAMAT TM instrument by performing 5 determinations of a high-HbF blood sample $(70 \%)$ followed by 5 determinations of a low-ḦF sample $(0.5 \%)$. We repeated the experiment 10 times, and then calculated the mean value of the ratio:

$$
\mathrm{K}=\frac{\left(\mathrm{l}_{1}-1 \mathrm{~s}\right)}{\left(\mathrm{h}_{5}-\mathrm{l}_{\mathrm{s}}\right)}
$$

The resulting "carry-over constant" of $1.4 \times 10^{-3}$ indicates the absence of sample-to-sample carry-over or incomplete column elution.

Table 1 shows the results of $\mathrm{HbS}$ assays in some subjects with the HbS trait.
Tab. 1. HbS percentage in 4 subjects with HbS-trait

\begin{tabular}{lll}
\hline Patient & DIAMAT TM & Electrophoresis \\
\hline A & $46 \%$ & $47 \%$ \\
B & $45.9 \%$ & $44.3 \%$ \\
C & $41.8 \%$ & $42 \%$ \\
D & $73 \%$ & $72 \%$ \\
\hline
\end{tabular}

\section{Discussion}

Among the various programs offered by the DIAMAT TM instrument, the basic routine program affords the elution and assay of glycated haemoglobin fractions and $\mathrm{HbF}$ in only 8 minutes.

Chromatography proved efficient and precise, especially for pathologic $\mathrm{HbF}$ values.

The HbF assay is linear up to $65 \%$ values; comparison with the alkali-resistance method revealed good correlation, even at high $\mathrm{HbF}$ values.

Thus the DIAMAT TM apparatus affords ready detection of most, cases of $\beta$-thalassaemia and $\mathrm{HbF}$ persistence without recourse to the more laborious and time-consuming method based on alkali resistance.

The same DIAMAT TM program also reveals HbS, which is eluted next to $\mathrm{HbA}$ (fig. 2). In such cases the instrument does not indicate the percentage of

TIME 85-10-30 12:20

SAMPLE NO. 008

$\begin{array}{lrrr}\text { Name } & \% & \text { TIME } & \text { AREA } \\ \text { AlA } & 0.3 & 1.9 & 9.80 \\ \text { A1B } & 0.6 & 2.4 & 22.29 \\ \text { F } & 0.7 & 3.0 & 26.40 \\ \text { AlC } & 5.0 & 4.3 & 173.71 \\ \text { A0 } & 93.4 & 6.0 & 3381.35 \\ \text { S/AO } & 0.0 & 6.4 & 3040.74 \\ \text { HBAIC } & 5.0 \% & \text { HBA1 } & 5.9 \%\end{array}$

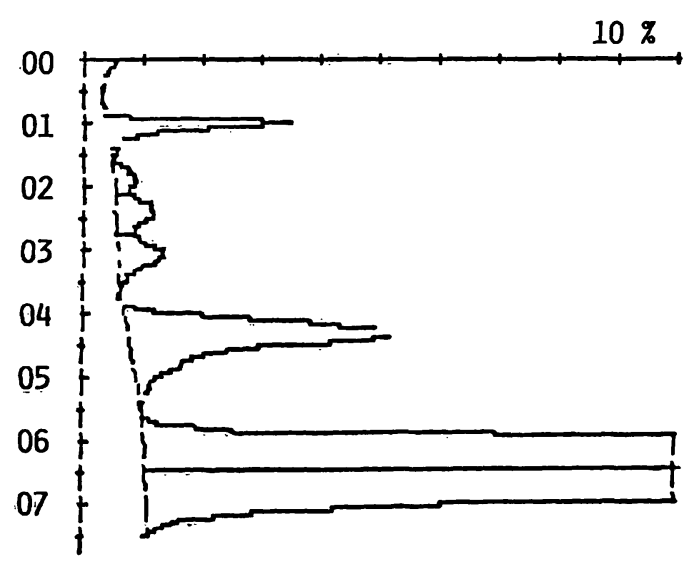

Fig. 2. Printout of sample with HbS. 
HbS directly but only its peak area, from which the percentage relative to total haemoglobin is readily calculated. The $\mathrm{HbS}$ area calculated by the integrator is in good aggreement with the percentage found by electrophoresis.

\section{References}

1. Betke, K., Mart, H. P. \& Schlicht, I. (1959) Nạture 184, 1877-1878.

2. Briere, R. O., Golias, T. \& Batsakis, J. (1965) Am. J. Clin. Pathol. 44, 695-701.

3. Robinson, A. R., Robson, M., Harrison, A. P. \& Zvelzer, W. W. (1957) J. Lab. Clin. Med. 50, 745-752.

4. Basset, P., Braconnier, F. \& Rosa, J. (1982) J. Chromat. 227, 267-340.

5. Kohn, J. \& Pagne, B. V. (1972) J. Clin. Pathol. 25, $830-831$.
As for the possible detection and assay of other haemoglobin subfractions, we are currently testing some software modifications and different elution buffers; preliminary resultș appear promising for $\mathrm{HbC}$ and $\mathrm{HbA}_{2}$.

i

6. Abraham, E. C., Carver, J., Döbler, J., Milner, P. F. \& Huisman, T. H. J. (1979) Hemoglobin 3, 341 - 351.

7. Gardiner, M. B., Carver, J., Abraham, B. L., Wilson, J. B. \& Huisman, T. H. J. (1982) Hemoglobin $6,1=13$.

8. Wilson, J. B., Headlee, M. E. \& Huisman, T. H. J. (1983) J. Lab. Clin. Med. 102, 174-186.

9. Kruiswijk, K. T., Diaz, D. P. \& Holtkamp, A. C. (1981) Clin. Chem. 27, 641-642.

10. Moore, N. A., Hickey, T. M. \& Kouns, D. M. (1985) Clin. Chem. 6, 413.

Dr. Sergio Brenna via Campo dei Fiori, 32 I-20026 Novate Milanese 